América sin nombre, n. ${ }^{\circ} 21$ (2016): 39-48

DOI: 10.14198/AMESN.2016.21.02

ISSN: 1577.3442 / eISSN: 1989-9831

Fecha de recepción: 22/08/2016

Fecha de aceptación: 15/11/2016
Puede citar este artículo como:

Aracil Varón, Beatriz. "La función evangelizadora del teatro breve en la Nueva Espańa del siglo xvI». Teatro breve virreinal. América Sin Nombre (Coordinador Miguel Zugasti), 21 (2016): 39-48, DOI: 10.14198/ AMESN.2016.21.02

Link para este artículo: http://dx.doi.org/10.14198/AMESN.2016.21.02

\title{
La función evangelizadora del teatro breve en la Nueva España del siglo XVI
}

\section{The Evangelization Function of the brief theater in New Spain during $16^{\text {th }}$ Century}

\author{
Beatriz Aracil Varón* \\ Universidad de Alicante
}

\begin{abstract}
Resumen
Concebido como instrumento eficaz en la labor de cristianización de la población indígena, el teatro evangelizador fue el primer producto cultural plenamente mestizo de la Nueva Espańa. Para desarrollarlo, los misioneros (en especial franciscanos) adaptaron a menudo al contexto americano formas dramáticas breves de la tradición peninsular, integradas en marcos celebrativos más amplios cuyas características fueron variando a lo largo del siglo Xvi de acuerdo, por un lado, a las diversas etapas del proceso evangelizador y, por otro, a las necesidades concretas de las distintas zonas del virreinato. El presente artículo aborda algunas de esas formas de teatro breve a partir de la funcionalidad que estas adquirieron en los distintos tipos de eventos de los que formaron parte a lo largo de ese primer siglo de la colonia.
\end{abstract}

Palabras clave: teatro de evangelización, Nueva España, formas teatrales breves, neixcuitilli.

\begin{abstract}
Conceived as an effective instrument for the Christianization of indigenous population, Evangelization Theatre was the first fully mestizo cultural product of New Spain. In its development, missionaries (particularly the Franciscans) tended to adapt brief Spanish dramatic forms to an American context, integrating them into broader celebratory frameworks having a wide range of characteristics across the $16^{\text {th }}$ Century in accordance with, on the one hand, the diverse stages of the evangelization process and, on the other hand, the specific needs of the different areas of the viceroyalty. This article considers some of these brief theatrical forms based on their functionality within the distinct types of events held during the first century of the colony.
\end{abstract}

Keywords: Evangelization Theatre, New Spain, brief theatrical forms, neixcuitilli.

* Doctora en Filología Hispánica. Profesora Titular de Literatura Hispanoamericana en la Universidad de Alicante (España). Especialista en teatro hispanoamericano colonial, se ha dedicado asimismo al estudio de la Crónica de Indias y su recuperación en la novela y el teatro latinoamericanos contemporáneos. Entre sus publicaciones afines a la temática del presente monográfico, cabe destacar, además de diversos artículos y capítulos de libros, los siguientes trabajos: El teatro evangelizador. Sociedad, cultura e ideología en la Nueva España del siglo XVI (Roma, Bulzoni, 1999); la coedición del volumen colectivo Fiesta y teatralidad de la pastorela mexicana (México, UNAM, 2004) y la coedición de Fiesta religiosa y teatralidad popular en México (América sin nombre, 2006). 
Abordar la actividad teatral en la América hispana durante el siglo XVI, es «hacer una historia de ausencias ${ }^{1}$ : la escasez de textos dramáticos conserva$\operatorname{dos}^{2}$ y lo esporádico de las noticias en torno a representaciones teatrales o a la actividad dramática de determinados autores, en cierta medida compensados por las descripciones de los cronistas sobre algunas puestas en escena que pudieron alcanzar cierta relevancia en su contexto, apenas ayudan a trazar un panorama que refleje en su justa medida la importancia (cuantitativa y cualitativa) del teatro en el marco social, cultural y religioso impuesto por el Imperio español en el territorio americano.

Lo que sí podemos afirmar con cierta seguridad, al menos por lo que respecta en concreto al ámbito novohispano, es que, si a fines del xvi se consolida un teatro destinado a la población española y crio$1 \mathrm{a}^{3}$, la primera mitad del siglo está marcada por el desarrollo de un teatro de carácter mestizo, el denominado "teatro evangelizador» o "teatro misionero», concebido como instrumento eficaz en la labor de cristianización de la población indígena, que fue promovido sobre todo por la orden franciscana y que tuvo su máximo esplendor en las décadas inmediatamente posteriores a la llegada de dicha orden a la Nueva España (1530 y 1540).

1. Utilizo esta expresión de Germán Viveros a propósito del teatro profano en Nueva España en el siglo Xvi (Viveros 25), que puede hacerse extensible a una parte importante de la actividad teatral en la América colonial, y muy especialmente al período objeto del presente estudio.

2. Los primeros textos dramáticos conservados de la América hispana pertenecen ya a la segunda mitad del xvi (es el caso de las obras de Juan de Cigorondo, Juan Bautista Corvera, Juan Pérez Ramírez, González de Eslava y otros). Contamos, sin embargo, con diversos manuscritos, a menudo anónimos, de autoría y datación incierta o manifiestamente tardía que, por su temática y estilo, podrían considerarse copias o reelaboraciones de obras de las primeras décadas de la colonia. Algunos de estos textos serán citados en las páginas que siguen como ejemplos del teatro misionero novohispano.

3. Desarrollado por compañías profesionales llegadas de la península o, en menor medida, americanas, y también por otros grupos sociales como los alumnos de las élites criollas educados en los colegios jesuitas, cuyas obras de corte humanístico traspasaron el ámbito de las aulas para exponerse al conjunto de la sociedad en festejos políticos o religiosos.

4. Aunque ya existía algún trabajo previo sobre el tema, la bibliografía en torno al teatro evangelizador novohispano ha adquirido cierta relevancia desde los años 70. En orden cronológico, resultan de interés los aportes de Brinckmann, Ravicz, Horcasitas, Arróniz, Partida, Aracil Varón y Sten (2000).
Inserta en lo que Robert Ricard denominó la "conquista espiritual de México», dicha actividad dramática abarcó -en palabras del propio Ricard«representaciones teatrales organizadas por los religiosos para los indios exclusivamente, en las cuales eran actores ellos mismos, y que se escribieron en su propia lengua» (304). En su intento de adaptar el cristianismo a un entorno del todo nuevo, los misioneros emprendieron esta especial forma de acercamiento a la nueva fe que, como la música o la pintura, vino a cubrir el triple objetivo de sustituir las fiestas paganas, facilitar la enseñanza de la doctrina cristiana a las masas indígenas y hacer esa enseñanza más interesante a los ojos de los indios. Para desarrollarla, debieron adaptar al nuevo contexto americano el drama religioso popular que, con una finalidad también edificante, llevaba desarrollándose en la península desde la Edad Media, labor para la cual resultó indispensable el conocimiento adquirido desde fechas tempranas sobre la lengua y las costumbres del mundo náhuatl.

Si bien en las décadas de mayor auge de este tipo de teatro tenemos noticias de algunas representaciones con gran aparato escénico y larga duración, como la puesta en escena del "universal juicio» llevada a cabo en la Ciudad de México en 1538 (en la que, según Bartolomé de las Casas, participaron como actores "ochocientos indios», tan bien interpretada «que si en Roma se hiciera, fuera sonada en el mundo", I, 214) o la de La conquista de Jerusalén, que tuvo lugar en Tlaxcala al año siguiente (ampliamente descrita por fray Toribio Motolinía en su Historia de los indios de la Nueva España, 202-213), lo habitual en este contexto debió ser -a juzgar por los documentos conservados- la composición de piezas breves integradas en un marco litúrgico-festivo más amplio. Es por ello que, en el presente estudio, se abordarán algunas de esas fórmulas de teatro breve manejadas por los misioneros precisamente a partir de la funcionalidad que estas adquirieron en los distintos tipos de eventos religiosos de los que formaron parte a lo largo de ese primer siglo de la colonia.

\section{La representación teatral como elemento esencial del festejo: autos en la celebración del Corpus y otras fechas destacadas del calendario litúrgico}

$\mathrm{Al}$ igual que el drama religioso medieval peninsular, el teatro evangelizador novohispano se desarrolló fundamentalmente en torno a las fechas más señaladas del calendario litúrgico, que determinaron a 
su vez la existencia de diversos ciclos temáticos: el de Pascua y Resurrección, el de Navidad, el ciclo bíblico (con obras basadas sobre todo en el Viejo Testamento), el hagiográfico y el mariano (Aracil Varón 131-132 y 232-250). Por su parte, el ciclo del Corpus Christi, que no había definido plenamente una temática relacionada con el misterio de la Eucaristía en la época que nos ocupa (las representaciones podían ser tanto de carácter bíblico como hagiográfico o mariano) $)^{5}$, había adquirido ya una gran importancia en la metrópoli que pronto se vio reflejada en la Nueva España y, sobre todo, por lo que atañe a la puesta en escena de las piezas, había convertido en un elemento de la tradición popular la ejecución de las mismas como parte de la procesión del Sacramento, en espacios destacados de su recorrido por las calles.

Un ejemplo del traslado de esta forma de representación al teatro evangelizador novohispano podría ser el festejo que sirvió de pretexto para la citada representación de La conquista de Jerusalén: la celebración del Corpus Christi en Tlaxcala en 1539. Tras la puesta en escena de este espectáculo, solo iniciada una vez que hubo «llegado el Santísimo Sacramento a la dicha plaza», la procesión se reanudó avanzando

entre unas calles hechas todas de tres órdenes de arcos medianos, todos cubiertos de rosas y flores muy bien compuestas y atadas; y estos arcos pasaban de mil y cuatrocientos, sin otros diez arcos triunfales grandes, debajo de los cuales pasaba toda la procesión [...]. Había también tres montañas contrahechas muy al natural con sus peñones, en las cuales se representaron tres autos muy buenos [...]: la tentación del Señor [...], cómo San Francisco predicaba a las aves [y] el sacrificio de Abraham (Motolinía, Historia 213-215).

Del mismo modo, según Motolinía (Historia 195196) $)^{6}$, el año anterior, con motivo de la festividad de San Juan, se organizaron "cuatro autos» que fueron representados en sus correspondientes tablados, ubicados en el recorrido de la procesión. El desarrollo de la fiesta mostró en esta ocasión una especial complejidad en cuanto a la integración en la misma tanto de las piezas dramáticas como de diversos elementos rituales: esta comenzó con la marcha de la comitiva

5. El auto sacramental surgirá en México a partir del último tercio del siglo xvi, como parte del teatro destinado a la población peninsular y criolla.

6. El pasaje es copiado por Las Casas (I, 213). hasta llegar al lugar donde se puso en escena la Anunciación de la Natividad de San Juan Bautista; la procesión continuó hasta el tablado donde se escenificó la Anunciación de Nuestra Señora y de ahí pasó al lugar de la tercera representación, la Visitación de Nuestra Señora a Santa Elisabet; finalizada ésta, se realizó la ceremonia litúrgica y, «después de misa se representó la Natividad de San Juan, y en lugar de la circuncisión fue bautismo de un niño de ocho días que se llamó Juan». Al acabar el auto, «los parientes y vecinos de Zacarías que se regocijaron con el nacimiento del hijo, llevaron presentes y comidas de muchas maneras, que puesta la mesa asentáronse a comer que era ya hora». En definitiva, en una misma ceremonia los frailes incorporaron la procesión, tres representaciones teatrales, una misa, una cuarta representación en el transcurso de la cual se celebró un bautizo real, y, por último, el festejo de dicho bautizo con una comida.

Como puede comprobarse en los pasajes citados, Motolinía define todas estas piezas representadas en el recorrido de la procesión como «autos» ${ }^{7}$, término frecuente en la tradición teatral peninsular de origen medieval ${ }^{8}$ que, como ha explicado Díez Borque, cubría durante el siglo XVI «un área específicamente teatral y, fundamentalmente, de temática religiosa» (19) y que podríamos definir de forma sencilla, según propone Flecniakoska, como "drame dévot en un acte» $(448)^{9}$. Los diversos tipos de autos se identificaron también en la Nueva España con los distintos ciclos temáticos propios de la tradición medieval (Bataillon), según se refleja en estos mismos pasajes y en otros del cronista franciscano como el incluido a propósito del auto sobre «la caída de nuestros primeros padres», representado en Tlaxcala como colofón a la procesión de la octava del último miércoles de Cuaresma de 1539 (Historia 200-202),

7. Incluso a propósito de la representación de «moros y cristianos» sobre la conquista de Jerusalén, afirma que «cuantos en este auto entraron, todos eran señores y principales» (Motolinía, Historia 204-205; la cursiva es mía).

8. Aunque podía ser sustituido por otros, como ocurre en el Códice de Autos Viejos, ya que -como nos recuerda Catalina Buezo- en el xvi «los límites entre farsas, autos, coloquios, entremeses y otras piezas no están bien prefigurados» (Buezo y Plaza Carrero 63).

9. A pesar de centrase en un período posterior al que nos interesa, esta obra es fundamental para el estudio de las características y evolución del «auto» hasta Calderón. Otro estudio clásico sobre el desarrollo del auto de 1500 a 1648 (aunque centrado en el auto sacramental) es el de Wardropper. 
en el que es posible observar, además, la habitual estructura tripartita de estas piezas ${ }^{10}$, con prólogo o introito, el auto propiamente dicho y una canción o villancico que contenía la idea básica de la obra y que, en este caso, fue cantado "por desecha, en canto de órgano»:

Para qué comió
la primer casada,
para qué comió
la fruta vedada.
La primer casada,
ella y su marido,
a Dios han traído
en pobre posada
por haber comido
la fruta vedada. (Motolinía, Historia 202)

Si la mayoría de los títulos de los autos comentados por Motolinía coinciden con los que aparecen documentados en la península (Adán y Eva, El sacrificio de Isaac, Las tentaciones de Cristo...) y sin duda se inscriben -como se ha señalado- en dicha tradición temática, lo más probable es que los textos novohispanos fueran compuestos para la ocasión por los misioneros, que adaptaron su contenido al nuevo contexto americano (Aracil Varón 232-250). Incluso en algunos casos, más allá de posibles concomitancias con temas habituales de la tradición peninsular, sería posible determinar un manejo directo de fuentes bíblicas, como seguramente ocurrió durante las fiestas de San Juan de 1538, para las cuales los franciscanos debieron "sacar en prosa» náhuatl con enorme fidelidad, y en el mismo orden en el que aparecen en el relato, los cuatro episodios del Evangelio de San Lucas (1,5-79) que corresponderían a los autos citados por Motolinía (la Anunciación de la Natividad de San Juan, la Anunciación de Nuestra Señora, la Visitación de Nuestra Señora a Santa Isabel y la Natividad de San Juan) ${ }^{11}$.

Respecto a la brevedad de los textos dramáticos, esta no siempre tuvo su correlato en la puesta en escena, que podía dilatarse o abreviarse por distintos

10. Ver Flecniakoska 269-312. Sobre la estructura, personajes y temas de los autos, ver Díez Borque 19-28.

11. En este caso, además, la composición de los autos se hizo con gran premura, ya que, según Motolinía: «sólo para sacarlos en prosa, que no es menos devota la historia que en metro, fue bien menester todo el viernes, y en sólo dos días que quedaban, que fueron sábado y domingo, lo deprendieron» (Historia 195-196). motivos: fray Toribio señala una duración de una hora para cada una de las dos primeras piezas de esta festividad de San Juan (probablemente debida a la introducción de los cantos) ${ }^{12}$, y respecto a la representación del auto de "la caída de nuestros primeros padres» apunta que «tardose en él gran rato, porque antes que Eva comiese ni Adán consintiese, fue y vino Eva, de la serpiente a su marido y de su marido a la serpiente, tres o cuatro veces, siempre Adán resistiendo» (Motolinía 195); en cambio, a propósito del auto del «sacrificio de Abraham» con el que finalizó el Corpus de 1539, el franciscano señala que "por ser corto y ser ya tarde no se dice más de que fue muy bien representado» (215).

\section{Teatro y sermón: la puesta en escena de exempla o neixcuitilli}

Frente a aquellos autos que, como los consignados por Motolinía en su Historia, se incorporaron a los solemnes festejos de fechas destacadas del calendario litúrgico durante las décadas de mayor auge de la "conquista espiritual», las fuentes novohispanas parecen reflejar, en las décadas siguientes ${ }^{13}$, la presencia de otro tipo de piezas breves de carácter evangelizador, con una puesta en escena menos elaborada, que se vincularían a la celebración litúrgica dominical, y más concretamente al contenido de los sermones pronunciados durante la misma.

No es de extrañar este manejo del teatro como complemento de la oratoria sagrada, dada la estrecha relación entre la representación y el sermón que las órdenes mendicantes (y especialmente los franciscanos) desarrollaron en Europa durante la Edad Media. El propio San Francisco, en su esfuerzo por renovar los métodos de instrucción del pueblo, manejó (y reformó) tanto el discurso persuasivo como la

12. Explica Motolinía que «representaron harto devotamente la anunciación de la Natividad de San Juan Bautista hecha a su padre Zacarías, que se tardó en ella obra de una hora, acabando con un gentil motete en canto de órgano. Y luego adelante en otro tablado representaron la Anunciación de Nuestra Señora, que fue mucho de ver, que se tardó tanto como en el primero" (Historia 196).

13. En las que se produce una decadencia del teatro evangelizador provocada, entre otros motivos, por la pérdida del poder de las órdenes mendicantes en la estructura eclesiástica y por la merma de la población nativa, que va a sufrir a su vez un progresivo desplazamiento en la sociedad novohispana (ver Aracil Varón 532-548). 
representación dramática, métodos que combinó en una predicación caracterizada precisamente por una mezcolanza de elementos en el intento de captar al auditorio (Manselli, en Il francescanesimo 122), que evolucionaría en los siglos siguientes hacia experiencias híbridas como el "sermón semidramático» (Doglio, en Il francescanesimo 19).

Con esa misma actitud ante la predicación, en la Nueva España los misioneros franciscanos habían hecho uso desde sus inicios de todo tipo de recursos persuasivos para transmitir su mensaje, lo cual implicó una estrecha relación entre el discurso retórico y la representación teatral. En este sentido, si algunas de las obras conservadas del teatro evangelizador ${ }^{14}$ han sido consideradas por la crítica moderna como "sermones dramatizados» ${ }^{15}$, es porque es posible observar en ellas el manejo de técnicas de persuasión propias de la oratoria sagrada (Aracil Varón 396-418) o incluso la incorporación de temas y rasgos estilísticos de la literatura moral náhuatl, transmitida a través de los huehuetlatolli o «discursos de ancianos» (Aracil Varón 360-362 y 414-416; Ruiz Bañuls, 2013, 79-122).

A menudo estas obras aparecen consignadas con el término neixcuitilli ${ }^{16}$, que Rémi Siméon, en su Diccionario de la lengua nábuatl o mexicana, define

14. Como ya he advertido, me refiero aquí a manuscritos ya tardíos que, sin embargo, pueden ser considerados copia o reelaboración de piezas dramáticas evangelizadoras del XVI. Una relación de textos de este tipo puede consultarse en Sten, 2000, 401-404. En las últimas décadas, sin embargo, se han localizado algunas piezas que sí podrían haber sido escritas a fines del XVI o comienzos del XVII: me refiero a Miércoles santo, dada a conocer en 1996 por Louise M. Burkhart, que pudo ser compuesta hacia 1590 en el colegio franciscano de Santa Cruz de Tlatelolco y, por tanto, constituir la copia más antigua conocida de un drama en náhuatl (Burkhart 3), y dos piezas sobre la Pasión de Cristo localizadas en Tlaxcala por Reyes García, una perteneciente a los archivos fiscales de Atlihuetzia y otra conservada en la fiscalía de San Simón Tlatlauhquitepec, Xaltocan; esta última (incompleta) ha sido publicada por Macuil en 2010 (La Pasión de Tlatlauhquitepec).

15. Es el caso de los manuscritos ya tardíos del Sacrificio de Isaac (Ricard 316; Ruiz Bañuls, 2010) o el Juicio final (Arróniz 28-29; Betancourt 36-37).

16. Así ocurre en las piezas Neixcuitilmachiotl motenehua Juicio Final (Horcasitas I, 703), Las ánimas y los albaceas, conservada con el título Neixcuitilli itechpa tlatohua yn animastin yhuan Avaceasme (Brinckmann 136), El mercader, cuyo título en el manuscrito es Neixcuitilli yn techpatlantohua yn pochtecatl (Horcasitas II, 121) o la que Cornyn y McAfee publicaron como La educación de los hijos, definida al final no en términos teatrales sino retóricos: «neixcuitilli s.v. Modelo, ejemplo tomado como base de un discurso o de un sermón» (318). En efecto, es la vinculación con el sermón la que otorga a estos «ejemplos» ese carácter moral ${ }^{17}$ destacado por la crítica respecto a algunas piezas, de mayor o menor extensión, que fueron compuestas para su puesta en escena de forma exenta ${ }^{18}$, pero también la que explica que las representaciones dramáticas pudieran servir en el contexto novohispano de "ilustración bíblica» de la predicación, de manera similar a lo ocurrido en la tradición medieval europea con la reproducción, a modo de exempla, de momentos de la vida de Cristo (Allegri 32).

por uno de los personajes como nexcuitilmachiyotlo «representación ejemplar» (Horcasitas II, 84).

17. Recordemos que este sentido moral es el que le dio al término exemplum la Antigüedad clásica (ver Covarrubias fol. 274) y el que todavía en el xvin le dará el Diccionario de Autoridades: «EXEMPLO: caso, suceso u hecho que se propone y refiere, o para que se imite y siga, siendo bueno y honesto, o para que se huya y evite, siendo malo».

18. Además de los títulos de piezas teatrales, tenemos, desde fechas muy tempranas, referencias documentales a representaciones teatrales que se definen con el mismo término. Así ocurre en los Anales mexicanos: «1531. xiij Acatl. Nican mochiuch neixcuitilli ycuac netlapacholoc. [1531. 13-cańa. Aquí se hizo una representación ejemplar de cuando en la tierra hubo anegamiento con agua (¿Diluvio?)] (I, 25; trad. facilitada por José Rubén Romero); en la memoria del cacique indígena don Toribio de Sandoval Martín Cortés, a propósito de una representación en Cuernavaca a inicios de la década de 1530: "Aquí ponemos que en nuestro entero juicio vimos el primer neixcuitilli y exemplo porque un demonio tentaba a los cristianos y entonces lo conjuraron para que no se apoderase de las almas y así habéis de hacer vosotros los que quedáis en el mundo" (trad. en Horcasitas I, 290); o en la Séptima Relación de Chimalpahin y la Historia general de Bernardino de Sahagún al referirse a la puesta en escena de un Juicio final en Tlatelolco en 1533: [Chimalpahin:] "Auh za no ycuac ynin mochiuh y neyxcuitilli yn ompa Santiago Tlatilulco Mexico yehuatl ca ynic tlamiz cemanahuatl; ce[n] ca quimahuizoque yn mizahique yn Mexica [y también fue cuando se hizo una representación teatral allá en Santiago Tlatelolco en México de cómo terminará el mundo; los mexicanos quedaron muy maravillados y espantados]» (Horcasitas I, 696); [Sahagún:] «tlatocati don pablo xochiquen in tenochtitla, in muchiuh tlatilulco uei tlamauizolli uei nexcuitilli inic tlamiz cemanauac [cuando reinaba don Pablo Xochiquen en Tenochtitlan se hizo en Tlatelolco una cosa maravillosa, una representación [teatral] ejemplar de cómo habría de terminar el mundo]» (Horcasitas I, 696). 
A este segundo tipo de neixcuitilli o ejemplos corresponderían las representaciones de la Pasión instauradas en la capital a fines del xvi por fray Francisco de Gamboa. Sobre ellas explica fray Juan de Torquemada en su Monarquía indiana que, en los tiempos en que Gamboa fue vicario de la capilla de San José de los Naturales,

se instituyeron unas representaciones de ejemplos, a manera de comedias, los domingos en la tarde, después de haber habido sermón; a los cuales dos actos, de viernes y domingo, es sin número la gente que se junta, así de indios como de españoles (Torquemada VI, 395).

Una actividad en la que el mismo Torquemada habría participado incluso con la composición de los textos dramáticos junto a otro franciscano, el padre fray Juan Bautista:

Yo [...] introduje las representaciones de los ejemplos los domingos, y hice en la lengua mexicana estas dichas comedias o representaciones, que fueron de mucho fruto a estas gentes, y ahora lo son, porque desde entonces ya se acostumbran, por algunos ministros, en muchas partes o haciéndolas ellos de nuevo, o aprovechándose de las muchas que yo tengo hechas y otras que el padre fray Juan Bautista, mi lector de teología, luz de esta santa provincia y de toda la Nueva España, hizo de mucha elegancia y erudición (Torquemada VI, 395).

Por otro lado, el mismo Bautista se refirió en el prólogo a su Confesionario en lengua mexicana y castellana (1599) a algunas obras teatrales que había compuesto con esta finalidad (y que, al parecer, finalmente no fueron impresas):

Tengo larga experiencia que con las comedias que de estos y de otros ejemplos he hecho representar las cuaresmas ha sacado nuestro Señor, por su misericordia, gran fruto, limpiado y renovado conciencias envejecidas en muchos años en ofensas suyas; y por esto, tengo hecho un libro de ellas en esta lengua mexicana, que mediante el divino favor saldrá presto a la luz (en Durán I, 701-702).

Los pasajes citados son interesantes no solo por los datos que aportan sobre estos «ejemplos» representados en torno a la Cuaresma y Semana Santa, sino también por la calidad de sus autores, cuya dedicación a una oratoria sagrada dirigida específicamente a la población indígena fue también muy significativa: Torquemada aclara en este mismo pasaje que fue el primero que predicó en lengua náhuatl los sermones de los viernes en compañía de Bautista (VI, 395), y debemos a este último tanto la publicación de numerosos huehuetlatolli prehispánicos ${ }^{19}$ (algunos de ellos ya plenamente cristianizados ${ }^{20}$ como de un Sermonario en lengua mexicana (1606). La interrelación entre sermón y teatro en la actividad de estos frailes queda de manifiesto, además, en el prólogo a dicho sermonario, cuando, al citar a Agustín de la Fuente como inestimable colaborador del libro, Bautista incluye un comentario al margen en el que hace referencia a esas piezas teatrales, también compuestas junto a este aventajado alumno del Colegio de Tlatelolco, que debían servir a su vez de complemento a la predicación:

Con su ayuda ha hecho el autor los tres libros de comedias que tiene para imprimir. El primero de la Penitencia y sus partes. El segundo de los principales Artículos de nuestra Santa Fe y Parábolas del Evangelio. El tercero de Vidas de Santos (Bautista, «Prólogo» [5] $)^{21}$.

En definitiva, parece evidente que este tipo de representaciones estrechamente vinculadas al sermón no solo fueron habituales en el ámbito novohispano de fines del xvi (al menos en la ciudad de México) ${ }^{22}$, sino que se consideraron lo suficientemente útiles como para que los textos dramáticos fueran impresos

19. Huehuetlatolli, que contiene las pláticas que los padres y madres hicieron a sus hijos y a sus hijas, y los señores a sus vasallos, todas llenas de doctrina moral y politica (1600). Edición moderna en León-Portilla y Silva Galeana.

20. Sobre el rescate y manejo de estos discursos para la predicación franciscana, ver Ruiz Bañuls, 2009, 103-233.

21. Facsímil del folio original disponible en https://archive.org/ stream/iesuchristosnofr00juan\#page/n23/mode/2up

22. Y al menos hasta un siglo después, a juzgar por el testimonio del franciscano Agustín de Vetancourt, sobre el que ya reparó Horcasitas: «Los sermones que en esta iglesia [San José de los Naturales] se predican en el discurso del año son muy continuos en particular en la cuaresma. Todos los domingos hay sermón por la mañana y a la tarde se representa un ejemplo historial que llaman neixcuitiles (...). Esto instituyeron los primeros padres porque como los naturales no tienen más entendimiento que los ojos, les ponen a la vista los misterios para que queden en la fe más firmes» (Teatro Mexicano. Descripción breve de los sucesos ejemplares (1698), en Horcasitas I, 527-528). 
(aunque el rescate de los mismos haya resultado hasta ahora infructuoso).

\section{Formas híbridas de representación en eventos cívico-religiosos}

En fechas cercanas a aquellas en las que Gamboa, Torquemada y Bautista organizaron sus «ejemplos» dramáticos, el también franciscano Alonso Ponce recorría las provincias de su jurisdicción como comisario de la orden en el virreinato. Su llegada se consideró un importante evento en los distintos pueblos visitados, y por ello se organizaron todo tipo de festejos para agasajarlo. Entre 1585 y 1588, Ponce presenció la representación de algunas piezas teatrales breves, como la referida a la "Parábola del rico avariento» en Techalutla (Jalisco), el 4 de marzo de 1587:

Había muchos arcos y ramadas e infinidad de indios, y acompañado de todos y de una danza llegó a la puerta del patio, donde, brevemente en lengua mexicana, representaron la historia del rico avariento en un tablado que para ello tenían hecho, a cuyo pie tenían un mitote o baile a su modo (Ciudad Real II, p. 152);

y de otras probablemente concebidas como pequeños textos que, sin embargo, se demoraron debido a su puesta en escena, como ocurrió con la Adoración de los Reyes Magos de Tlaxomulco (Jalisco), que nuestro fraile registra el 6 de enero de 1587, durante la cual,

desde lo alto de un cerro, de los que estaban junto al pueblo, vinieron bajando los Reyes a caballo tan despacio y poco a poco, así por la gravedad, como porque el cerro es muy alto y tiene muy áspero el camino, que se tardaron casi dos horas en bajar y llegar al patio (Ciudad Real II, 101).

Pero lo que me interesa destacar en este apartado es la frecuencia con la que el comisario franciscano da cuenta de la integración en el festejo de escenificaciones en las que la danza y/o la mímica tienen un valor fundamental ${ }^{23}$. Algunas de ellas podrían considerarse «cuadros vivientes» o "invenciones», al modo de las «rocas» de la procesión del Corpus española ${ }^{24}$. Es el

23. La mayor parte de estas escenificaciones fueron reseńadas en Pazos 182-186. Ver asimismo Aracil Varón 208-209.

24. Este tipo de escenificaciones pudo haber formado parte de los métodos evangelizadores en la Nueva España caso de la representación de San Pedro y San Andrés en Purenchéquaro (Michoacán) el 9 de noviembre 1586):

[En una ramada] estaba un indio viejo que representaba a San Pedro, con unas grandes llaves en la mano y en la otra una red grande levantada en alto, en la cual había asidos algunos peces; en otra ramada estaba San Pedro y San Andrés, el San Pedro con otras llaves y el San Andrés con otra red, la cual extendió al tiempo que el padre comisario pasaba, y parecieron en ella muchos pececillos de los de aquella laguna (Ciudad Real II, 78);

la de la impresión de las llagas de San Francisco en Tamatzula (Jalisco) el 26 de febrero de 1587:

A la puerta de la iglesia tenían hecha una ramada, y en lo alto de ella puestos dos indios en hábito de frailes representando a nuestro padre San Francisco, cuando en el monte Alberne recibió las llagas de mano de nuestro Señor en figura de serafín; y hacíanlo tan al vivo, que el que representaba a nuestro Padre estuvo grandísimo rato levantados los brazos, y puestos con las manos de la manera que estaba cuando las recibió, y le suelen pintar, sin menear pie ni mano ni cabeza y sin pestañear ni quitar los ojos de un crucifijo que estaba en lo alto, que cierto provocaba a devoción (Ciudad Real II, p. 147);

o la de la lucha entre el Arcángel San Miguel y Lucifer el 27 de febrero de 1587 en Zapotlán (Jalisco):

Había muchas ramadas, y en la penúltima dellas estaba en lo alto un indio como ángel, representando a San Miguel, con una espada en la mano, como que hería a Lucifer, el cual era otro indio vestido a manera y figura de dragón, que estaba dando bramidos debajo de los pies del ángel (Ciudad Real II, p. 148).

desde fechas muy tempranas. Así, en un fragmento de su Apologética (copiado de un texto de Motolinía anterior a la redacción definitiva de la Historia), Bartolomé de las Casas explica que, para el Corpus de 1538, los tlaxcaltecas prepararon ciertos decorados naturales: «En la primera destas montańas estaba la representación de Adán y Eva y la serpiente que los engañó. En la segunda, la tentación del Señor. En la tercera, San Jerónimo, y en la cuarta, nuestro padre San Francisco» (Las Casas I, 211). El uso de la expresión «estaba la representación» sugiere la posibilidad de que en aquella ocasión no hubiera desarrollo argumental sino simples «cuadros vivientes». 
Otras son más bien «danzas dramatizadas» en las que entrevemos una presencia muy marcada de elementos propiamente indígenas, tanto respecto a la puesta en escena ${ }^{25}$ como en lo que atañe a la temática de las mismas. En cuanto a la representación, son frecuentes las referencias a los papeles cómicos de los actores indígenas (fruto de una tradición histriónica ya consignada a propósito de las fiestas prehispánicas en las crónicas misioneras ${ }^{26}$ ), como vemos en la danza de la muerte ejecutada el 9 de noviembre de 1586 en Purenchéquaro (Michoacán):

Salió un indio en figura de la muerte, y con él otro en figura y traje de negro diciendo muchas gracias, así a los frailes como a los indios y a la mesma muerte, con la cual fue un rato jugando al quince con unos naipes viejos, y cuando no jugaba tañía una guitarra y decía donaires, hablando como negro bozal (Ciudad Real II, 78);

o la danza del Nombre de Jesús contra los demonios de S. Juan de Tikax (Yucatán), que tuvo lugar el 17 de septiembre de 1588, sobre la cual explica Ponce:

[Salió una danza] de muchachos en figura de negrillos, representando a los demonios, los cuales, a unas coplas que les cantaban a canto de órgano, en oyendo en ellas el nombre de Jesús, caían todos en tierra y temblaban haciendo mil visajes y meneos en señal de temor y espanto (Ciudad Real II, 363).

Por lo que respecta a la temática, la finalidad evangelizadora se entremezcla con el reflejo de la situación social más inmediata en escenificaciones como las llamadas «danzas de chichimecas»: el indio salvaje del norte, que todavía debe ser cristianizado, asume el papel del infiel en estas representaciones que adaptan al nuevo contexto la tradición europea de «moros y cristianos», reproduciendo la propia situación de guerra de frontera que se estaba viviendo en esas décadas en el virreinato (Aracil Varón 499-501). Así,

25. Esta presencia indígena en la puesta en escena de las piezas es algo propio del teatro evangelizador desde sus inicios. Dos valoraciones distintas de la misma pueden consultarse en Sten, 1974, 65-76; y Aracil Varón 288-292.

26. Ya fray Toribio Motolinía comentaba sobre la existencia de actores o «representantes» en el México prehispánico que estos eran "como truhanes; andan sobresaliendo, haciendo mil visajes y diciendo mil gracias que hacen reír a cuantos los ven y oyen: unos andan como viejas, otros como bobos» (Memoriales 183). por ejemplo, en la escenificación ofrecida a Ponce en Patamba (Michoacán) el 18 de noviembre de 1586,

llegó [un indio] a caballo delante del padre comisario, $y$ en lengua castellana le dijo que fuese bien venido a su tierra, y que porque había allí chichimecas, venía él con sus compañeros a asegurarle el paso y guardarle, y que no tuviese miedo que allí estaba él; luego comenzaron todos a correr a una parte y a otra por entre aquellos pinos, dando voces y diciendo y repitiendo muchas veces 'Santiago, Santiago', y al cabo de un rato salieron de entre las matas de improviso diez o doce indios de a pie, vestidos como chichimecas (Ciudad Real II, 82 $)^{27}$.

En definitiva, en estas breves representaciones que inician su desarrollo en la segunda mitad del xvi en zonas rurales, con una población todavía autóctona casi en su totalidad y alejadas de los grupos social y culturalmente influyentes de la capital, se observa ya una progresiva apropiación de las propuestas dramáticas misioneras por parte de las comunidades indígenas, lo que favorecerá la pervivencia de las mismas (con sus necesarias variantes) como formas de expresión identitaria hasta la actualidad ${ }^{28}$.

\section{Conclusión}

Como he intentado demostrar en las páginas precedentes, la necesidad de trasmitir el mensaje evangélico a la población nativa llevó a los misioneros (especialmente franciscanos) a desarrollar con éxito en Nueva España diversas formas de teatro breve que se revelaron eficaces instrumentos catequísticos. Los modelos de estas representaciones deben buscarse en la tradición medieval peninsular (teatral y parateatral), pero los frailes supieron adaptar esta experiencia previa al nuevo contexto americano para lograr la implicación de la población nativa en una actividad dramática con fundamental presencia en las celebraciones religiosas.

Las diversas etapas del proceso evangelizador, por un lado, y las necesidades concretas de las distintas zonas (geográficas y culturales) del virreinato, por

27. Una relación de otras danzas de chichimecas presenciadas por Ponce en esos meses puede consultarse en Aracil Varón 209.

28. Un interesante análisis de las danzas de chichimecas desde el siglo Xviı hasta la época contemporánea es el de Bonfiglioni. 
otro, exigieron el desarrollo de diversos contextos litúrgico-festivos y, con ello, de fórmulas dramáticas capaces de adaptarse a dichos contextos. La puesta en escena de autos de tradición medieval propios de festividades como el Corpus Christi, la dramatización de exempla como complemento al sermón dominical y la incorporación de la mímica y la danza en sencillas escenificaciones destinadas a exaltar el triunfo del cristianismo sobre la idolatría fueron, a juzgar por los testimonios conservados, soluciones válidas para los misioneros cuyo manejo se prolongaría incluso más allá del primer siglo de la colonia ${ }^{29}$.

\section{Bibliografía}

AA.VV. Il francescanesimo e il teatro medievale. Atti del Convegno nazionale di studi (San Miniato, 8-10 octubre 1982). Florencia: Società Storica della Valdelsa, 1984.

Allegri, Luigi et alii. «El teatro medieval». Ínsula, 527 (noviembre 1990): 1-3, 11-21 y 31-32.

Alvar, Carlos, Ángel Gómez Moreno y Fernando Gómez Redondo. La prosa y el teatro en la Edad Media. Madrid: Taurus, 1991.

Anales Mexicanos. Anónimo en lengua mexicana. México: Vargas Rea, 1948.

Aracil Varón, Beatriz. El teatro evangelizador. Sociedad, cultura e ideología en la Nueva España del siglo XVI. Roma: Bulzoni, 1999.

Aracil Varón, Beatriz, y Mónica Ruiz Bañuls, (coords.). Fiesta religiosa y teatralidad popular en México. Monográfico de América sin nombre, 8 (2006).

Arroniz, Othón. Teatro de evangelización en Nueva España. México: UNAM, 1979.

BAtaillon, Marcel. "Ensayo de explicación del auto sacramental». Varia lección de clásicos españoles. Madrid: Gredos, 1964: 183-205.

Bautista, fray Juan (O.F.M.). Sermonario en lengua mexicana. México, en casa de Diego López Dávalos, 1606. [Accesible en: https://archive.org/details/ iesuchristosnofr00juan].

Betancourt, Helia Gloria. Teatro franciscano de evangelización en Nueva España. Philadelphia: University of Pennsylvania, 1990.

29. En este sentido, cabe admitir, además, la influencia de algunas de estas experiencias dramáticas en el desarrollo de un teatro religioso de carácter popular (con formatos de mayor o menor extensión) que todavía cuenta con una arraigada tradición entre la población indígena de México (sobre este tipo de teatro son de interés, entre otros, los estudios recopilados en Aracil Varón y Ruiz Bañuls, 2006).
Bonfiglioli, Carlo. "Chichimecas contra franceses: de los 'Salvajes' y los Conquistadores». Jesús Jaúregui y Carlo Bonfiglioli (eds.). Las danzas de conquista, I. México contemporáneo. México: CONACULTA-FCE, 1996: 91-115.

BRINCKMANN, Bärbel. Quellenkritische Untersuchungen zum mexikanischen Missioschauspiel, 1532-1732. Hamburg: Renner, 1970.

Buezo, Catalina, y Nuria Plaza Carrero. "Tipología de las formas breves». Javier Huerta Calvo (dir.). Historia del teatro breve en España. Madrid-Frankfurt: Iberoamericana-Vervuert, 2008: 63-119.

Burkhart, Louise M. Holy Wednesday. Philadelphia: University of Pennsylvania, 1996.

Ciudad Real, fray Antonio de (O.F.M.). Tratado curioso y docto de las grandezas de la Nueva España. Relación breve y verdadera de algunas cosas de las muchas que sucedieron al Padre fray Alonso Ponce en las provincias de la Nueva España siendo comisario general de aquellas partes. 2 vols. Ed. Josefina Quintana y Víctor M. Castillo Ferreras. México: UNAM, 1993.

Covarrubias, Sebastián de. Tesoro de la lengua castellana, $o$ española. Madrid, por Luis Sánchez, 1611. [Accesible en línea: http://www.cervantesvirtual.com/obra-visor/delorigen-y-principio-de-la-lengua-castellana-o-romanceque-oy-se-vsa-en-espana-compuesto-por-el--0/ $\mathrm{html} /]$.

Díez Borque, José María. Los géneros dramáticos en el siglo XVI. Madrid: Taurus, 1987.

Durán, Juan Guillermo. Monumenta Catechetica Hispanoamericana. 2 vols. Buenos Aires: Facultad de Teología-Pontifica Universidad Católica de Argentina, 1984 y 1990.

FleCNIAKOSKA, Jean Louis. La formation de l'auto réligieux en Espagne avant Calderon (1550 1635). Montpellier: Paul Dehan, 1961.

Horcasitas, Fernando. El teatro nábuatl I. Épocas novohispana y moderna [1974]. México: UNAM, 2004.

Horcasitas, Fernando. Teatro nábuatl II. María Sten y Germán Viveros (coords.). México: UNAM, 2004.

Las Casas, Bartolomé de (O.P.). Apologética historia de las Indias. 2 vols. Madrid: Atlas (BAE 105-106), 1958.

Motolinía, fray Toribio de Benavente (O.F.M.). Historia de los indios de Nueva España. Ed. Georges Baudot. Madrid: Castalia, 1985.

Motolinía, fray Toribio de Benavente (O.F.M.). Memoriales e Historia de los indios de la Nueva España. Madrid: Atlas (Biblioteca de Autores Españoles 240), 1970.

Partida, Armando. Teatro de evangelización en náhuatl. México: Consejo Nacional para la Cultura y las Artes, 1992. 
La Pasión de Tlatlauhquitepec. Obra de teatro tlaxcalteca en náhuatl del siglo XVI. Ed. Raúl Macuil Martínez. Tlaxcala: Gobierno del Estado de Tlaxcala-Instituto Tlaxcalteca de la Cultura, 2010.

Pazos, Manuel. «El teatro franciscano en México durante el siglo XvI». Archivo Ibero-Americano, 2a época, 11:42 (1951): 129-189.

Ravic, Marylin Ekdahl. Early Colonial Religious Drama in Mexico from Tzompantli to Golgotha. Washington: The Catholic University of America Press, 1970.

Real Academia Española. Diccionario de Autoridades. Madrid: Francisco del Hierro (1726-1739). [Accesible en línea a través del Nuevo tesoro lexicográfico de la lengua española: http://web.frl.es/DA.html].

Ricard, Robert. La conquista espiritual de México. México: FCE, 1986.

Ruiz Bañuls, Mónica. El «huehuetlatolli» como discurso sincrético en el proceso evangelizador novohispano del siglo XVI. Roma: Bulzoni, 2009.
Ruiz Bañuls, Mónica. «Cuando el sermón se vuelve teatro: El sacrificio de Isaac en el contexto evangelizador novohispano». Arrabal, 7-8 (2010): 287-293.

Ruiz Bañuls, Mónica. Literatura y moral en el México virreinal. Alicante: Instituto Alicantino de Cultura Juan Gil-Albert, 2013.

SimÉon, Rémi. Diccionario de la lengua náhuatl o mexicana. Trad. Josefina Oliva de Coll. México: Siglo XxI, 1988.

STEN, María. Vida y muerte del teatro náhuatl: el Olimpo sin Prometeo. México: Secretaría de Educación Pública, 1974.

STEN, María (ed.). El teatro franciscano en la Nueva España. Fuentes y ensayos para el estudio del teatro de evangelización en el siglo XVI. México: UNAM-FONCA, 2000.

Viveros, Germán. Escenario novohispano. México: Academia Mexicana de la Lengua, 2014.

WARDROPPER, Bruce W. Introducción al teatro religioso del Siglo de Oro. Madrid: Revista de Occidente, 1953. 